\title{
Providing Japanese health care information for international visitors: digital animation intervention
}

\author{
Mariko Nishikawa ${ }^{1 *}$, Masaaki Yamanaka², Junko Kiriya ${ }^{3}$ and Masamine Jimba ${ }^{3}$
}

\begin{abstract}
Background: Over 24 million international visitors came to Japan in 2016 and the number is expected to increase. Visitors could be at a risk of illness or injury that may result in hospitalization in Japan. We assessed the effects of a four-minute digital animation titled Mari Info Japan on the level of anxiety experienced by international visitors to Japan.

Methods: We conducted a non-randomized, controlled study at Narita International Airport outside Tokyo in December 2014. On the first day, we recruited international visitors for the intervention group at predetermined departure gates and, the following day, we sampled visitors for the control group at the same gates. We repeated this procedure twice over 4 days. The intervention group watched the digital animation and the control group read a standard travel guidebook in English. After receiving either intervention, they completed a questionnaire on their level of anxiety. The outcome was assessed using the Mari Meter-X, The State-Trait Anxiety Inventory Form Y (STAI-Y), and a face scale, before and immediately after the intervention. We analyzed data with Wilcoxon rank sum tests.
\end{abstract}

Results: We recruited 265 international visitors (134 in the intervention group, 131 in the control group), 241 (91\%) of whom completed the questionnaire. Most of them had no previous Japanese health information before arrival in Japan. The level of anxiety about health services in Japan was significantly reduced in the intervention group (Mari Meter-X median: -5 and $0, p<0.001$ and STAI-Y median: -3 and $0, p<0.001$ ). The face scale analysis showed no significant difference.

Conclusions: Watching a digital animation is more effective in reducing anxiety among international visitors to Japan compared with reading a standard brochure or guidebook. Such effective animations of health information should be more widely distributed to international visitors.

Trial registration: UMIN-CTR (University Hospital Medical Information Network Center Clinical Trials Registry), UMIN000015023, September 3, 2014.

Keywords: Digital animation, Health information, International visitors, Japan

\section{Background}

The number of international visitors worldwide has grown sharply, from 0.65 billion in 1996 to 1.22 billion in 2014 [1]. In Japan, the number increased from 8.6 million in 2010 to over 24 million in 2016, attracted by a government advertising campaign [2]. Furthermore, this

\footnotetext{
* Correspondence: mn378@nyu.edu

${ }^{1}$ Department of Global Health and Nursing, Graduate School of Nursing, University of Human Environments, Nagoya, 3-220, Ebata cho, Obu city, Aichi 474-0035, Japan

Full list of author information is available at the end of the article
}

number will rise further as the Olympic games will be held in Tokyo in 2020 [3].

International visitors are at risk of injury or illness in visiting countries. Of the total number of American visitors who returned from Asia and Sub-Saharan Africa, approximately $75 \%$ experienced travel-related illnesses due to gastrointestinal, febrile, and dermatologic diseases [4]. Other problems were sun-related conditions, sexually transmitted diseases, insect bites, jellyfish stings, or animal-related injuries [5-7]. In Japan, international visitors went to hospitals with symptoms of diarrhea,

(C) The Author(s). 2018 Open Access This article is distributed under the terms of the Creative Commons Attribution 4.0 International License (http://creativecommons.org/licenses/by/4.0/), which permits unrestricted use, distribution, and 
abdominal pain, or fever $[8,9]$. In extreme cases, they required surgery $[10,11]$. Some international visitors eschewed a hospital when ill because of the expense or their unfamiliarity with hospital procedures [12].

As the number of international visitors sharply increases, there will be a greater demand for appropriate knowledge to deal with prevention and treatment. Major international events, such as the Olympic games, require effective health information strategies for international visitors [13-16].

Meanwhile, there are three main problems with health information for international visitors. First, in their home countries, health education for travelers is usually provided through brief notes in brochures, arbitrary and subjective material on the Internet, or in guidebooks [17-19]. Moreover, although the Health Ministries of many countries provide health related information, it is mostly for their own citizens going abroad and the majority of pre-travel health information is about infectious diseases in developing countries [7, 20, 21]. Information on other health related topics for tourists coming from abroad are also required in the host countries.

Second, the effectiveness of pre-travel education depends on the health facility visited [19, 22]. In some countries, primary physicians and nurses may not be upto-date about travel health issues [23].

Third, succinct travel guidelines are available for Japanese nationals [24], but they are inappropriate for international visitors. For example, international visitors are primarily concerned about paying medical expenses, communication, and informed consent at health facilities, but sufficient information to reduce these concerns are inadequately provided [12].

Host countries have a stake in providing information to international visitors about healthy living and health systems [5], illness prevention [6, 25] and procedures to access health facilities $[5,12,26]$. Travelers have a healthy and enjoyable experience when timely and critical knowledge is available before visiting other countries $[27,28]$. Hosts can also use such information when their friends or relatives visit them and ask about health issues [29-31].

Effective intervention is vital to providing practical information. A digital animation can provide culturally and linguistically appropriate information about preventive health behaviors [32-34]. An earlier study showed that an educational digital video of in vitro fertilization (IVF) was a more effective medium for understanding health risks than a brochure, for couples starting their first cycle of IVF [35]. This tool can be applied to conveying information on travel medicine to international visitors. In this study, we examined the effect of a four-minute digital animation titled Mari Info Japan (Fig. 1, Additional files 1 and 2)

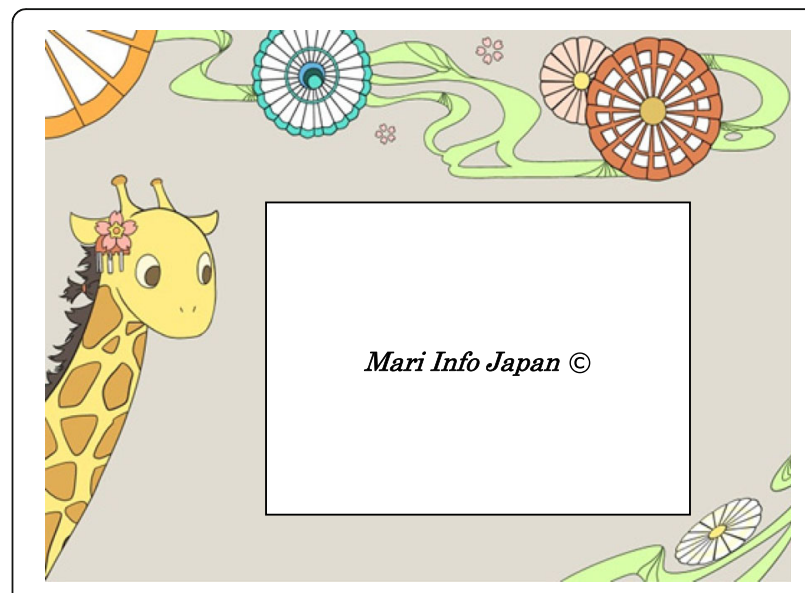

Fig. 1 Digital animation: Mari Info Japan

on the level of anxiety experienced by international visitors to Japan.

\section{Methods \\ Study design and procedures}

We conducted a non-randomized controlled study on the effectiveness of video instruction among international visitors to Japan on the level of anxiety experienced by them. In this intervention study, we recruited participants at departure gates for the United States, Canada, and the United Kingdom at Narita International Airport, Japan, from December 21 to 24, 2014.

The participants answered a questionnaire about anxiety before receiving either intervention. Thereafter, they answered another questionnaire to evaluate any changes to their anxiety (Fig. 2). We evaluated the differences in anxiety level before and after the intervention, and between the intervention and control groups.

\section{Participant entry Sample size}

We estimated a sample size of 120 visitors in each group to have a $95 \%$ confidence level and $80 \%$ power to detect a difference of 3.1 in the questionnaire score in our analyses.

\section{Eligibility}

We recruited international visitors at departure gates to the aforementioned countries, where English is the primary language. They had more time to participate in this study while waiting for their flights than those who had just arrived. In addition, targeting gates for English speaking countries enabled us to find more people eligible for this study. The questionnaire was only in English to avoid any discrepancy in translation. We approached adults who were 20 years old or over, who could read, listen to, and write English. To maximize the 
Before intervention

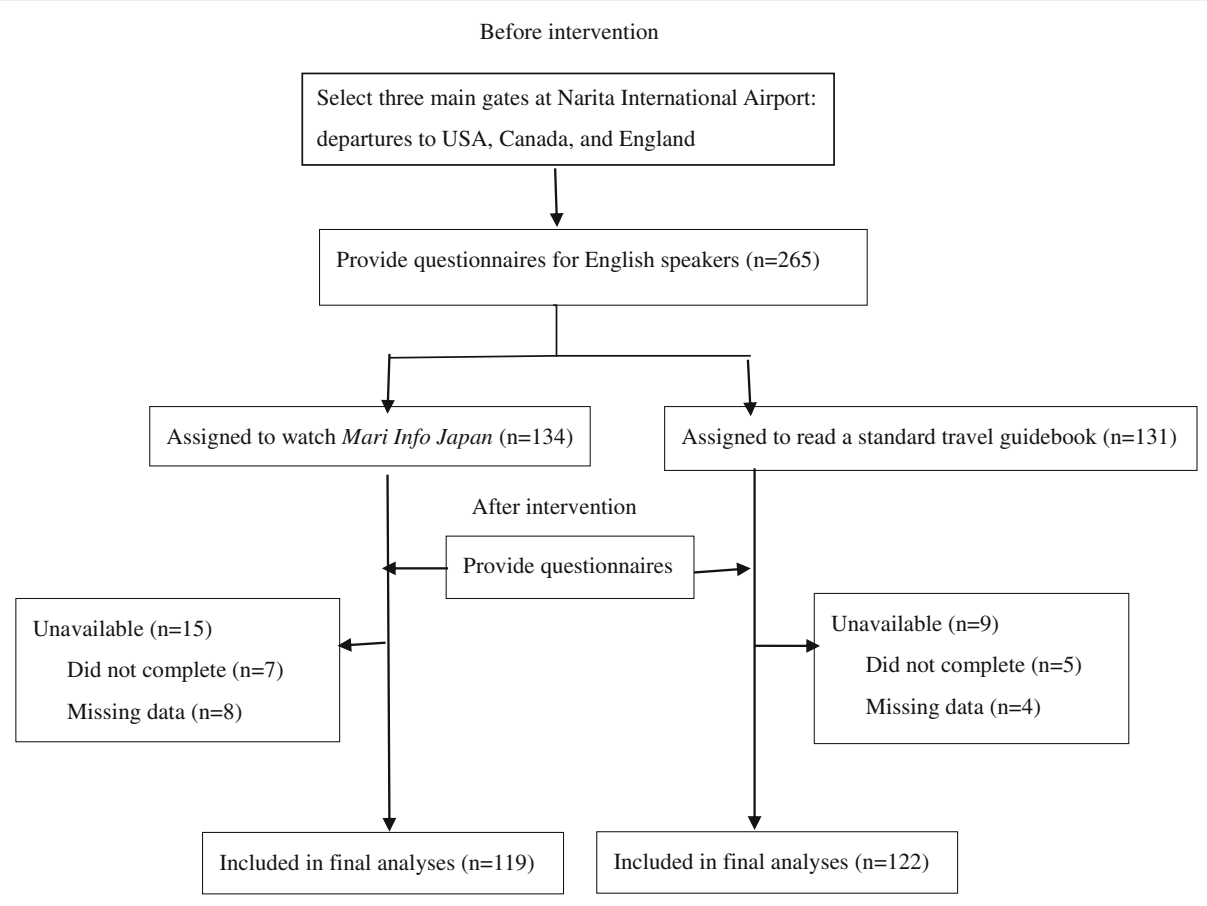

Fig. 2 Trial profile

validity of responses to our questionnaire, we adhered to a strict criterion. We recruited only those who were calmly seated at their gate at least $2 \mathrm{~h}$ prior to departure. This ensured they could concentrate on their responses without being rushed.

\section{Enrolment procedure}

Since we recruited visitors in our study at a small number of gates, it was difficult to provide both the experimental and control interventions to them at the same time while avoiding contamination. We sampled participants for the intervention group at a particular gate on the first day and recruited the control group the following day. We repeated this procedure twice over 4 days. We invited those who were already at the gates when we started recruitment. Thereafter, we asked every person who arrived at the gates if they would participate in this study. We recruited participants based on their willingness to tell us about their knowledge of the Japanese health system and health information. If they were travelling with friends or family members, we asked them to respond to the questionnaire individually.

\section{Interventions}

We left participants alone in both groups after providing a short explanation on how to view the video (in the intervention group) and answer the questionnaire to avoid any distraction.

\section{Intervention procedure}

The intervention group watched a four-minute digital animation in English titled Mari Info Japan (Fig. 1). This animation aimed to provide information on health care system in Japan for international visitors. Its content is based on a previous study, which found that international visitors' main concern was how to visit health facilities [12]. It started with traditional Japanese music and contained 11-items (see Fig. 1, Additional files 1 and 2). We provided an $8 \times 5$-in. digital notepad and a headset to each visitor.

\section{Control procedure}

The control group read a simple information sheet in English, adopted from a standard travel guidebook [24] (see Additional file 3), which was expected to take approximately $3 \mathrm{~min}$ to finish reading.

\section{Outcome assessment}

The primary outcome of this study was the level of anxiety the visitors experienced about the Japanese health system and visiting health facilities. We assessed the outcome using STAI-Y, Mari Meter-X and a face scale before and after the visitors participated in the interventions.

(1) STAI-Y [36] is a 40-item questionnaire, using a four-point Likert-type scale. Twenty questions were about their state anxiety, which is the level of 
anxiety they feel when imagining they became ill. The other 20 questions were about trait anxiety. This reveals the level of anxiety that they generally feel in their day-to-day lives. The visitors completed both the state anxiety and trait anxiety questions before the trial. After the trial, the visitors answered only about their state anxiety. The STAI-Y scores are separated into state anxiety (20-80 points) and trait anxiety (20-80 points).

(2) Mari Meter-X $[12,31]$ is a 15 -item questionnaire using a five-point Likert-type scale (see Additional file 4), which examines the level of anxiety regarding visiting health facilities in Japan. The total score ranged from 15 to 75 points.

(3) The face scale [37] measured the visitors' feelings as indicated by face illustrations on a six-point Likerttype scale. They were asked to choose one face that represented their overall feelings at the time of data collection. It is the easiest and simplest way to express feelings. We assessed feelings the participants expressed simply using this face scale as well as detailed feelings measured with the above-mentioned questionnaires.

We used a demographic questionnaire (Table 1), the Mari Meter-X, STAI-Y and face scale. The visitors took about $15 \mathrm{~min}$ to complete the questionnaires. While they were watching the digital animation, one of the coauthors was nearby to answer any questions and collect the device after viewing. At no stage, did we hurry, chat with, or interrupt the visitors while they were completing the questionnaire.

\section{Other information}

As this was a non-randomized controlled study, we collected data on the background of the visitors, such as age, sex and previous visit to Japan, their home countries and visits to health facilities during their stay in Japan to determine if the characteristics of the visitors were balanced between the groups, as well as to detect factors that could affect the outcome other than the intervention.

\section{Bias prevention}

We could not ensure that the visitors were blind to their group allocation. However, there was very little chance that the visitors would know if they were either in the intervention or control group as we recruited visitors for each group on different days. Furthermore, the person who analyzed the data was not aware of the participants' intervention allocation.

\section{Data analysis}

For the main outcome, we analyzed the difference in median scores for the Mari Meter-X, STAI-Y state anxiety, and face scale before and after the intervention for each group with a two-sided Wilcoxon signed rank test. We compared differences in the before and after intervention scores between groups and conducted a multiple regression including all other variables to evaluate the effectiveness of the intervention, adjusted for other potential factors that affect the outcome. We conducted all statistical analyses using the JMP statistical package (version 11.0).

\section{Results}

In our study, 300 international visitors were approached and 265 agreed to participate in the study. We excluded data from 24 visitors (9\%) for various reasons: 12 did not complete either the intervention or the questionnaire because they started boarding or fell asleep during the intervention, while 12 questionnaires contained missing data (Fig. 2). We analyzed data from a total of 241 visitors, 119 in the intervention group and 122 in the control group.

\section{Characteristics of visitors and baseline comparison}

Table 1 shows a summary of the basic characteristics of the intervention group $(n=119)$ and control group $(n=122)$. The groups were balanced with respect to baseline characteristics, except for "visiting a medical facility in Japan," which was greater in the control group $(n=40 ; 33 \%)$ than in the intervention group $(n=15 ; 13 \%)$ $(p<0.001)$. More than half of the visitors were men in both groups. Over $40 \%$ belonged to the 20-30-year agebracket in both groups. Both groups had no travel coordinator and stayed in Japan for a median of 10 days. Over half of the visitors came to Japan two or more times in both groups. In total, $86 \%$ of the visitors in both groups held medical insurance. The reasons for not possessing travel insurance were viewing it as an unnecessary expense, having confidence in their health status, or not knowing the issues.

For the question on what to do when they get sick or injured during their trip, the most common responses were find a hospital $(n=138)$, look for a pharmacy $(n=67)$, call the consulate for their home country $(n=45)$, ask at hotel reception $(n=40)$, call an ambulance $(\mathrm{n}=40)$, call their tour conductor $(n=12)$, and other $(n=36)$. Both groups had little knowledge of Japanese health information. Among the visitors, 96 ( $81 \%$ of the total) in the intervention group and 100 ( $82 \%$ of the total) in the control group did not obtain health information before coming to Japan. Their sources of information were brochures, websites, hospital or clinic in their home country, colleagues, and 
Table 1 Demographic profile of participants

\begin{tabular}{|c|c|c|c|c|}
\hline & & & & $n=241$ \\
\hline Participant characteristics & & $\begin{array}{l}\text { Intervention group } \\
\qquad n=119 n(\%)\end{array}$ & $\begin{array}{l}\text { Control group } \\
n=122 n(\%)\end{array}$ & $p$ \\
\hline \multirow[t]{2}{*}{ Gender $(n=237)$} & Male & $76(64)$ & $68(57)$ & ] 0.370 \\
\hline & Female & $42(36)$ & $51(43)$ & \\
\hline \multirow[t]{4}{*}{ Age $(n=241)$} & $20<30$ & $69(59)$ & $54(44)$ & ] 0.166 \\
\hline & $30<40$ & $27(23)$ & $29(24)$ & \\
\hline & $40<50$ & $12(10)$ & $19(15)$ & \\
\hline & $\leqq 50$ & $11(8)$ & $20(16)$ & \\
\hline \multirow[t]{2}{*}{ Travel with conductor $(n=241)$} & Yes & $1(1)$ & $3(2)$ & ] 0.325 \\
\hline & No & $118(99)$ & $119(92)$ & \\
\hline Visiting days $^{\mathrm{b}}(n=241)$ & & 10 & 10 & - \\
\hline \multirow[t]{2}{*}{ Visiting times $(n=241)$} & Once & $51(43)$ & $45(37)$ & ] 0.329 \\
\hline & More than once & $68(57)$ & $77(63)$ & \\
\hline \multirow[t]{2}{*}{ Visiting medical facility $(n=240)$} & Yes & $15(13)$ & $40(33)$ & ]$<0.001^{* * *}$ \\
\hline & No & $104(87)$ & $81(67)$ & \\
\hline \multirow[t]{2}{*}{ Medical Insurance $(n=240)$} & Yes & $102(86)$ & $104(86)$ & ] 0.504 \\
\hline & No & $17(14)$ & $17(14)$ & \\
\hline \multirow[t]{4}{*}{ Reason to not have insurance ${ }^{a}$} & Did not know & 2 & 5 & - \\
\hline & Have confidence & 4 & 6 & - \\
\hline & Unnecessary expense & 10 & 6 & - \\
\hline & Other & 0 & 3 & - \\
\hline \multirow[t]{2}{*}{ Previous health information $(n=241)$} & Yes & $23(19)$ & $22(18)$ & ] 0.796 \\
\hline & No & $96(81)$ & $100(82)$ & \\
\hline \multirow[t]{4}{*}{ Source of the information ${ }^{a}$} & Brochure & 6 & 9 & - \\
\hline & Web & 12 & 5 & - \\
\hline & Health Facilities from home country & 2 & 3 & - \\
\hline & Colleagues and friends & 7 & 11 & - \\
\hline \multirow[t]{11}{*}{ Regions ( $n=241$ ) } & USA & $62(52)$ & $62(51)$ & - \\
\hline & Canada & $9(7)$ & $10(8)$ & - \\
\hline & China & $10(9)$ & $0(0)$ & - \\
\hline & UK & $7(6)$ & $21(17)$ & - \\
\hline & Indonesia & $6(5)$ & $0(0)$ & - \\
\hline & France & $3(3)$ & $3(3)$ & - \\
\hline & Germany & $4(3)$ & $0(0)$ & - \\
\hline & Australia & $3(3)$ & $3(3)$ & - \\
\hline & New Caledonia & $4(3)$ & $3(2)$ & - \\
\hline & Singapore & $2(2)$ & $3(2)$ & - \\
\hline & Other (11 countries) & $9(7)$ & $17(14)$ & - \\
\hline STAI - Y (trait anxiety score) before the trial ${ }^{b}(n=241)$ & & 61 & 61 & - \\
\hline
\end{tabular}

${ }^{\mathrm{a} M u l t i p l e}$ answers

${ }^{\mathrm{b}}$ Median

friends. Their countries of origin were well balanced between groups: the United States of America, Canada, the United Kingdom, France, and Australia.
However, only participants in the intervention group came from China, Germany, Indonesia, New Caledonia, and Singapore. 


\section{Reliability}

The high reliability of the Mari Meter- $X$ was confirmed by a Cronbach's alpha internal consistency reliability coefficient of 0.94, and the coefficient for the STAI-Y was 0.92 in this study.

\section{Statistical analysis}

Table 2 shows scores for both groups, before and after intervention, analyzed by Wilcoxon signed rank tests. There was no significant difference in the STAI-Y trait anxiety scores, which evaluated their general feeling before receiving the intervention, between the intervention and control groups. A statistically significant reduction in the Mari Meter-X score before and after the intervention was observed in the intervention group (median changed from 46 to $39, p<0.001$ ). Similarly, the reduction in STAI-Y state anxiety scores before and after receiving the intervention was statistically significant (median changed from 50 to $43, p<0.001$ ). However, the difference in the face scale score before and after intervention was not statistically significant.

In the control group, the Mari Meter- $X$ score did not decrease much from before to after the intervention, whereas the STAI-Y state anxiety score was reduced. The face scale showed no difference before and after the intervention. The Mari Meter- $X$ showed that the participants were more likely to be concerned about paying medical expenses $($ median $=4)$, language communication $($ median $=4)$, and informed consent (median $=3.5)$ in visiting health facilities.

Table 3 shows the comparison of the two groups after the intervention by Wilcoxson rank sum test. The Mari Meter- $X$ score was reduced more in the intervention group than in the control group (median: -5 and 0 , respectively, $p<0.001)$. The STAI-Y state anxiety was lower in the intervention group than in the control group (median: -3 and 0 , respectively, $p<0.001$ ). However, the face scale score did not differ between the two groups.

We found statistically significant differences between groups in countries of origin and experience of visiting medical facilities. However, the multiple regression analysis using STAI-Y scores showed that the intervention was still effective after adjusting for these factors. We found that no factors included in this study affected the effect of the intervention on the outcome.

\section{Discussion}

This study found that the digital animation of the health system in Japan reduced concerns related to healthy living and illness prevention (measured with Mari Meter-X) and the intensity of feelings of anxiety (measured with STAI-Y). However, we did not see significant change in their feelings expressed using the face scale. Our results are similar to those in a previous study using digital animation in another health field, examining behavioral change in handwashing with soap to reduce diarrhea and respiratory infections [33]. We also found that the majority of international visitors did not obtain information regarding the Japanese health system before coming to Japan.

The main finding shows that viewing a comprehensive, yet succinct digital animation provides visitors with knowledge on how to access medical care or contact emergency services. Digital animation is more effective as it summarizes the most basic information to access health services in Japan. Presenting information with voice and animation makes it easier for the audience to understand the points in a short time than reading printed texts. Having prior knowledge of the health

Table 2 Outcomes for before vs. after test for same groups by Wilcoxon signed rank test

\begin{tabular}{|c|c|c|c|c|c|c|c|c|c|}
\hline & \multicolumn{4}{|c|}{ Before } & \multicolumn{4}{|c|}{ After } & \multirow[t]{3}{*}{$p$-value } \\
\hline & & (Median) & & & & (Median) & & & \\
\hline & Q1 & Q2 & Q3 & Range & Q1 & Q2 & Q3 & Range & \\
\hline Intervention group & & & & & & & & & $(n=119)$ \\
\hline Mari Meter-X & 37 & 46 & 55 & $15-70$ & 29 & 39 & 43 & $15-65$ & $0.001^{* * *}$ \\
\hline STAI-Y: state anxiety & 38 & 50 & 59 & $30-72$ & 33 & 43 & 50 & $30-69$ & $0.001^{* * *}$ \\
\hline Face Scale & 0 & 1 & 2 & $0-5$ & 0 & 1 & 2 & $0-4$ & 0.278 \\
\hline Control group & & & & & & & & & $(n=122)$ \\
\hline Mari Meter-X & 35 & 46 & 55 & $15-75$ & 35 & 44 & 55 & $15-75$ & 0.214 \\
\hline STAI-Y: state anxiety & 40 & 52 & 58 & $30-70$ & 39 & 48 & 57 & $30-69$ & $0.007^{* *}$ \\
\hline Face Scale & 0 & 1 & 2 & $0-5$ & 0 & 1 & 2 & $0-5$ & 0.577 \\
\hline $\begin{array}{l}\text { Q1 The first quartile } \\
\text { Q2 The second quartile } \\
\text { Q3 The third quartile } \\
{ }^{* *} p<0.01 \\
p<0.001\end{array}$ & & & & & & & & & \\
\hline
\end{tabular}


Table 3 Outcomes for intervention vs. control group by Wilcoxon rank sum test

\begin{tabular}{|c|c|c|c|c|c|c|c|c|c|}
\hline & Interv & $n n=$ & & & Cont & $=122$ & & & $p$ value \\
\hline & & $(\mathrm{Me}$ & & & & (Mec & & & \\
\hline & Q1 & Q2 & Q3 & Range & Q1 & Q2 & Q3 & Range & \\
\hline Mari Meter-X & -15 & -5 & 0 & $(-54)-18$ & -1 & 0 & 1 & $(-17)-42$ & $0.001^{* * *}$ \\
\hline STAI-Y: state anxiety & -11 & -3 & 0 & $(-37)-27$ & -3 & 0 & 0 & $(-16)-20$ & $0.001^{* * *}$ \\
\hline Face Scale & 0 & 0 & 0 & $(-2)-4$ & 0 & 0 & 0 & $(-3)-3$ & 0.705 \\
\hline
\end{tabular}

system and how to access medical care may reduce their anxiety [38]. The reason why face scale scores did not differ between the two groups after the intervention may be that the visitors started thinking about health care more seriously, realizing the risks after watching Mari Info Japan even though it was entertaining.

One possible explanation for the large proportion of international visitors, who did not obtain information regarding the Japanese health system before coming to Japan, is that they assume a developed country such as Japan has a similar public health system as in their home country. Although the information might have been available, the visitors did not access the latest health guidelines before travelling [38].

This study has several strengths. First, this study is the first to rate the effectiveness of a unique digital animation of Japanese health information on the anxiety experienced by international visitors. Second, the baseline demographic factors of participants were well-balanced between the two groups. The only exception was that participants who had visited medical facilities in Japan were more frequent in the control group, while those who were from China, Germany, Indonesia, New Caledonia, and Singapore were only in the intervention group. Third, sampling contamination was unlikely as we conducted the research with intervention and control groups on different days. Lastly, this study has a comparatively high participation rate of $88 \%$ (265 out of 300). Targeting those who were leaving Japan and waiting for their flights at the gates might have helped it as they had time to participate in this study.

This study also has some limitations. First, we could not ensure the participants were blind to their group assignment due to the nature of the interventions. However, there was very little chance that they viewed the other intervention and knew that they were allocated to a different intervention. In addition to the participants, the researchers who conducted the data collection and data analyses were not blinded to the group allocation. Second, we did not randomly assign participants to groups, which means that although we adjusted the effect of the intervention for other factors that could affect the outcome, there is still a chance that unknown factors, such as having friends in Japan and duration of their stay in Japan, might have affected the results. We could not examine if these factors were balanced between the intervention and control groups.

\section{Implications and future study}

Our results revealed the advantages of distributing health information prior to visiting countries through simple and comprehensive methods. Additionally, we need to continuously update the content of health information based on recent events and provide a more effective dissemination of health information to international visitors prior to their arrival in Japan. Examples include web-based digital quizzes, information on multilingual TV channels popular among international visitors, and smart-phone applications. These tools and procedures to improve educational and communication structures will facilitate health care for international visitors to Japan. Future study on ways to provide this kind of information to international visitors on their arrival or during their stay at different places is required. A randomized controlled trial (RCT) will provide stronger evidence for the effectiveness of the intervention while avoiding unknown confounding factors.

\section{Conclusions}

This study found that watching a digital animation is more effective in reducing anxiety among international visitors to Japan compared with reading a standard brochure because it presents the summary of important information in an enjoyable but succinct way. Introducing similar digital animations of health information as a main tool to provide necessary information to international visitors on their arrival may contribute to reducing their anxiety and avoiding troubles associated with health clinic visits.

\section{Additional files}

Additional file 1: Contents of the information for the intervention group. The title is Mari Info Japan. It shows the headings for the digital animation for this study. (DOC $42 \mathrm{~kb}$ ) 
Additional file 2: Mari Info Japan in English. It shows the full version of the digital animation for this study. (WMV $8291 \mathrm{~kb}$ )

Additional file 3: Contents of information for the control group. It shows a simple information sheet in English for this study. (DOC $42 \mathrm{~kb}$ )

Additional file 4: Mari Meter- $X$ questionnaire which examines the level of anxiety regarding visiting health facilities in Japan. Mari Meter-X questionnaire used to obtain primary data. It shows the full version of the questionnaire for this study. (DOC $51 \mathrm{~kb}$ )

\section{Abbreviations}

NRS: Non-randomized controlled study; RCT: Randomized controlled trial; STAI-Y: The State-Trait Anxiety Inventory Form-Y

\section{Acknowledgements}

The authors would like to thank all international visitors who participated to this study. We thank Yuko Tsuda, Keiko Kono and Ayami Kondo for helping with the control and intervention sampling.

\section{Funding}

Mariko Nishikawa, RN, MPH was funded by the Japanese government Grants-in-Aid for Challenging Exploratory Research 2010-2012 (22659436) and 2014-17 (26671047)

\section{Availability of data and materials}

Please contact the first author for raw data.

\section{Authors' contributions}

MN, MJ and MY jointly designed and developed the study, MY and MN created the animation, MN and MYcarried out the data collection. MN, MY and JK analyzed the data. MN, MJ and JK wrote the manuscript. All authors regularly reviewed manuscript drafts and approved the final version.

\section{Ethics approval and consent to participate}

The Ethics Committee of Hiroshima International University (HIU) approved the research design of this study on September 3, 2014 (approval number 14-103). The participants were introduced to the study and briefed on the objectives. Verbal informed consent was obtained from all participants prio to the intervention. The Ethics Committee of HIU accepted verbal informed consent because of the non-sensitive nature of the study

\section{Competing interests}

The authors declare that they have no competing interests.

\section{Publisher's Note}

Springer Nature remains neutral with regard to jurisdictional claims in published maps and institutional affiliations.

\section{Author details}

'Department of Global Health and Nursing, Graduate School of Nursing, University of Human Environments, Nagoya, 3-220, Ebata cho, Obu city, Aichi 474-0035, Japan. ${ }^{2}$ Department of Maritime Science and Technology, Japan Coast Guard Academy, Kure, Japan. ${ }^{3}$ Department of Community and Global Health, Graduate School of Medicine, The University of Tokyo, Tokyo, Japan.

Received: 10 January 2018 Accepted: 7 May 2018

Published online: 21 May 2018

\section{References}

1. World Bank Group: International tourism, number of departures 2016 https://data.worldbank.org/indicator/ST.INT.DPRT?end=2014\&start= 1995\&view=chart. Accessed 3 April 2017.

2. JNTO: 2016 Visitor arrivals \& Japanese overseas travelers. http:// wwwjntogojp/jpn/statistics/data_info_listing/pdf/fotufe0000009gpp-att/ 160615monthlypdfpdf Accessed 31 Oct 2017, [in Japanese].

3. Ministry of Justice: e-Stat 2016. http://www.e-stat.go.jp/SG1/estat/List. do?lid=000001177523. Accessed 1 July 2017, [in Japaneses].

4. Leder K, Torresi J, Libman MD, Cramer JP, Castelli F, Schlagenhauf $\mathrm{P}$, et al. GeoSentinel surveillance of illness in returned travelers, 2007-2011. Ann Intern Med. 2013;158(6):456-68.
5. Leggat PA, Harrison SL, Fenner PJ, Durrheim DN, Swinbourne AL. Health advice obtained by tourists travelling to magnetic island: a risk area for 'Irukandji' jellyfish in North Queensland, Australia. Travel Med Infect Dis. 2005:3(1):27-31.

6. Hainsworth T. Travel health: reducing the preventable risks. Nurs Times. 2002;98(29):35-7.

7. Schlagenhauf $P$, Weld L, Goorhuis A, Gautret P, Weber R, von Sonnenburg F, et al. Travel-associated infection presenting in Europe (2008-12): an analysis of EuroTravNet longitudinal, surveillance data, and evaluation of the effect of the pre-travel consultation. Lancet Infect Dis. 2014;15(1):55-64.

8. Yamagishi S, Sakuma Y, Miyauchi K, Matsumoto A, Horikawa S, Shibui Y, et al. The anxiety for medical services system in inbound tourists to Japan. J International Health, [in Japanese]. 2008;23(4):273-9. [in Japanese]

9. Matsuda N, Naito T, Uehara Y, Hisaoka T. Reasons for Outpartient visits by foreign Travellers to an urban hospital in Tokyo. The 14th conference of the International Society of Travel Medicine. Quebec. Int Soc Travel Med. 2015.

10. Osegawa M, Morio H, Nomoto K, Nishizawa M, Sadahiro T. Present medical practice and problems in emergency disease in foreign travelers requiring admission. Japan Emergency Med J. 2002;13(11):703-10. [in Japanese]

11. Murakoshi $H$, Asano $Y$, Iwase $T$, Akanuma M. Five year trend in diseases contracted by non-Japaneses travelers of airport. Japan Society of Aerospace and Environmental Medicine. 2011;48(4):75. [in Japanese]

12. Nishikawa M, Niiya K, Okayasu M, Yamanaka M. Concerning visits to a hospital among foreign visitors in Japan: creating an anime multiplelanguage DVD Japan Society for the Promotion of Science,. 2013, [in Japanese].

13. Smallwood CAH, Arbuthnott KG, Banczak-Mysiak B, Borodina M, Coutinho AP, Payne-Hallström L, et al. Euro 2012 European football championship finals: planning for a health legacy. Lancet. 2014;383(9934):2090-7.

14. Memish ZA, Zumla A, Alhakeem RF, Assiri A, Turkestani A, Al Harby KD, et al. Hajj: infectious disease surveillance and control. Lancet. 2014;383(9934): 2073-82.

15. Khan K, Memish ZA, Chabbra A, Liauw J, Hu W, Janes DA, et al. Global public health implications of a mass gathering in mecca, Saudi Arabia during the midst of an influenza pandemic. J Travel Med. 2010;17(2):75-81.

16. Beres LK. Missed opportunities: HIV and the 2010 FIFA world cup. Public Health. 2011;125(10):725-6.

17. Thava Seelan S, Leggat PA. Health advice given by general practitioners for travellers from Australia. Travel Med Infect Dis. 2003;1(1):47-52.

18. Zwar N, Streeton CL. Travel health advisory group. Pretravel advice and hepatitis a immunization among Australian travelers. J Travel Med. 2007;14(1):31-6.

19. Hoveyda N, McDonald P, Behrens RHA. description of travel medicine in general practice: a postal questionnaire survey. J Travel Med. 2004:11(5):295-9.

20. Costa M, Oberholzer-Riss M, Hatz C, Steffen R, Puhan M, Schlagenhauf P. Pre-travel health advice guidelines for humanitarian workers: a systematic review. Travel Med Infect Dis. 2015;13(6):449-65.

21. Hill DR, Behrens RH. A Survey Of travel clinics throughout the world. In., vol 3. Massachusetts: Blackwell publishing Itd; 1996: 46-51.

22. Piotte $E$, Bellanger AP, Piton G, Millon L, Marguet P. Pre-travel consultation: evaluation of primary care physician practice in the Franche-Comte region. J Travel Med. 2013;20(4):221-7.

23. Huang H-L, Chiu T-Y, Huang K-C, Cheng S-Y, Yao C-A, Lee L-T. Travel-related mosquito-transmitted disease questionnaire survey among health professionals in Taiwan. J Travel Med. 2011;18(1):34-8.

24. Rowthorn C, Bender A, Crawford L, Holden T, McLachlan C, Milner R, et al, Japan-lonely planet travel guide. Lonely Planet. 2011:744-5.

25. Davies SC, Karagiannis T, Headon V, Wiig R, Duffy J. Prevalence of genital chlamydial infection among a community sample of young international backpackers in Sydney, Australia. Int J STD AIDS. 2011;22(3):160-4.

26. Ashley DVM, Gordon-Strachan G, Reece MH, Ashley DEC. Challenges for health and tourism in Jamaica. J Travel Med. 2004;11(6):370-3.

27. Bauer IL. Knowledge and Behavior of tourists to Manu National Park, Peru, in relation to Leishmaniasis. J Travel Med. 2002;9(4):173-9.

28. Wadhwaniya S, Hyder AA. Pre-travel consultation without injury prevention is incomplete. J Travel Med. 2013;20(4):217-20.

29. Behrens RH, Stauffer WM, Barnett ED, Loutan L, Hatz CF, Matteelli A, et al. Travel case scenarios as a demonstration of risk assessment of VFR travelers: introduction to criteria and evidence-based definition and framework. J Travel Med. 2010;17(3):153-62. 
30. Van Herck K, Van Damme P, Castelli F, Zuckerman J, Nothdurft H, Dahlgren $\mathrm{AL}$, et al. Knowledge, attitudes and practices in travel-related infectious diseases: the European airport survey. J Travel Med. 2004;11(1):3-8.

31. Nishikawa M, Niiya K, Kimura M. Addressing practical issues related to nursing care for international visitors to Hiroshima. Rev Esc Enferm USP. 2014;48(2):299-307.

32. Gunaratnam P, Sestakova L, Smith M, Torvaldsen S. Evaluation of a multilingual oral health DVD for newly arrived refugees. Health Promot $J$ Austr. 2013;24(2):159.

33. Biran A, Schmidt W-P, Varadharajan KS, Rajaraman D, Kumar R, Greenland K, et al. Effect of a behaviour-change intervention on handwashing with soap in India (SuperAmma): a cluster-randomised trial. Lancet Global Health. 2014;2(3):e145-54.

34. Skinner CS, Buchanan A, Champion V, Monahan P, Rawl S, Springston J, et al. Process outcomes from a randomized controlled trial comparing tailored mammography interventions delivered via telephone vs. DVD. Patient Educ Couns. 2011:85(2):308-12.

35. Hope N, Rombauts L. Can an educational DVD improve the acceptability of elective single embryo transfer? A randomized controlled study. Fertil Steril. 2010;94(2):489-95.

36. Spielberger CD, Gorssuch RL, Lushene PR, Vagg PR, Jacobs GA. Manual for the State-Trait Anxiety Inventory. California: Consulting Psychologists Press; 1983.

37. Magaret ND, Clark TA, Warden CR, Magnusson AR, Hedges JR. Patient satisfaction in the emergency department-a survey of pediatric patients and their parents. Acad Emerg Med. 2002;9(12):1379-88.

38. Flaherty GT, Chen B, Avalos G. Individual traveller health priorities and the pre-travel health consultation. J Travel Med. 2017;24(6)

Ready to submit your research? Choose BMC and benefit from:

- fast, convenient online submission

- thorough peer review by experienced researchers in your field

- rapid publication on acceptance

- support for research data, including large and complex data types

- gold Open Access which fosters wider collaboration and increased citations

- maximum visibility for your research: over $100 \mathrm{M}$ website views per year

At BMC, research is always in progress.

Learn more biomedcentral.com/submissions 